\title{
DSC STUDY OF PEFLOXACIN MESYLATE AND ITS MIXTURES WITH DIFFERENT EXCIPIENTS
}

\section{K. SWATHI", N. SUNITHA AND N.RAMA RAO AND M. NAGA RAJU}

Chalapathi Institute of Pharmaceutical Sciences-522 206, LAM, Guntur (Dist.), A.P

*Corresponding Author: Dr. K. Swathi: E Mail: khaggaswathi@gmai.com

Received 20 ${ }^{\text {th }}$ Feb. 2021; Revised $18^{\text {th }}$ Mar. 2021; Accepted 16 ${ }^{\text {th }}$ April. 2021; Available online $1^{\text {st }}$ Dec. 2021

\section{https://doi.org/10.31032/IJBPAS/2021/10.12.5747}

\begin{abstract}
In this study, it was studied the thermal decomposition of pefloxacin mesylate and some mixture with excipients containing the same active compound using DSC technique. The kinetic parameters were obtained from DSC curves using nitrogen under dynamic atmosphere and maintaining at constant temperature range. The data showed that the pefloxacin mesylate -active substance is thermally more stable than the mixtures with any excipient. The decrease in stability was attributed to the presence of excipients in formulation and to their possible interactions with the pefloxacin mesylate the difference in stability is bigger between the pure substance and the mixture with the magnesium stearate.
\end{abstract}

Keywords: Pefloxacin mesylate ; degradation behaviour; excipient; activation energy INTRODUCTION

Calorimetry is a primary technique for organic compounds with potential measuring the thermal properties of materials pharmaceutical action can be of great use for to establish a connection between determining their physical and chemical temperature and specific physical properties stability $[\mathbf{1}, \mathbf{3}]$. Calorimeters are used of substances and is the only method for frequently in chemistry [3], biochemistry [4, direct determination of the enthalpy 5] cell biology [6], biotechnology [7], associated with the process of interest $[\mathbf{1}, \mathbf{2}]$. pharmaceology [8] and recently in The application of thermal methods to ananoscience [9] to measure thermodynamic 
properties of the biomolecules and nanosized materials. Amongst various types of calorimeters, differential scanning calorimeter (DSC) is a popular one. DSC is a thermal analyis apparatus measuring how physical properties of a sample change, along with temperature againtst time [10]. In other words, the device is a thermal analysis instrument that determines the temperature and heat flow associated with material transitions as a function of time and temperature [11]. During a change in temperature, DSC measures a heat quantity, which is radiated or absorbed excessively by the sample on the basis of a temperature difference between the sample and sample with excipients $[\mathbf{1 0}, \mathbf{1 1}]$.

The compatibility studies using thermal analysis present advantage the to readily available knowledge of any physical and chemical interactions between drugs and excipients which might cause changes of chemical nature, stability, solubility, absorption and therapeutic response of drugs. Thermal techniques have been increasingly used for quick evaluation of possible incompatibility between formulation components through comparison of thermal curves of pure substances with curve obtained from a 1:1 mixture [13]. The furnace is heated at a linear heating rate, and the heat is transferred to the sample and reference pan through the thermoelectric disk $[11,12]$.

Differential scanning calorimetry (DSC) is the most frequently used thermal analysis technique alongside TGA, TMA and DMA. DSC is used to measure enthalpy changes due to changes in the physical and chemical properties of a material as a function of temperature or time. The method allows you to identify and characterize materials. Differential scanning calorimetry is fast, very sensitive and easy to use. DSC is a thermodynamically tool for direct assessment of the heat energy uptake, which occurs in a sample within a regulated increase or decrease in temperature. The calorimetry is particularly applied to monitor the changes of phase transitions $[\mathbf{1 4}, \mathbf{1 5}]$.

DSC is commonly used for the study of biochemical reactions, which is named as a single molecular transition of a molecule from one conformation to another [14]. Thermal transition temperatures ( $\mathrm{Tt}$; melting points) of the samples are also determined in solution, solid, or mixed phases such as suspensions.

In a basic DSC experiment, energy is introduced simultaneously into a sample cell (which contains a solution with the molecule of interest) and a reference cell (containing 
only the solvent). Temperatures of both cells are raised identically over time. The difference in the input energy required to match the temperature of the sample to that of the reference would be the amount of excess heat absorbed or released by the molecule in the sample.

The compatibility studies using thermal analysis present advantage the to readily available knowledge of any physical and chemical interactions between drugs and excipients which might cause changes of chemical nature, stability, solubility, absorption and therapeutic response of drugs. Thermal techniques have been increasingly used for quick evaluation of possible incompatibility between formulation components through comparison of thermal curves of pure substances with curve obtained from a 1:1 mixture [12]. If mixture curve represents thermal peaks sum observed for the individual components, there is no interaction and therefore no physicochemical incompatibility between drug and excipient [13-18]. In this paper, thermoanalytical techniques were used to study thermal behaviour, compatibility with excipients and kinetic analysis under nonisothermal (dynamic) conditions of pefloxacin mesylate. This substance is an antibiotic from the cephalosporin family, known as a first generation cephalosporin used to treat certain infections caused by bacteria such as pneumonia and bone, ear, skin, and urinary tract infections.

Pefloxacin is a fluoroquinolone antibiotic with broad-spectrum antimicrobial activity. Pefloxacin inhibits the activity of microbial DNA gyrase and topoisomerase IV. This disrupts DNA replication and prevents cell division.

Pefloxacin's formula is presented in Figure 1.

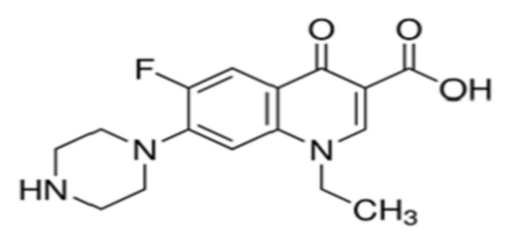

Figure 1: Structure of pefloxacin mesylate

The Molecular formula of Pefloxacin mesylate is $\mathbf{C}_{\mathbf{1 8}} \mathrm{H}_{\mathbf{2 4}} \mathrm{FN}_{\mathbf{3}} \mathrm{O}_{\mathbf{6}} \mathrm{S}$

The IUPAC name is 1-ethyl-6-fluoro-7-(4methylpiperazin-1-yl)-4-oxoquinoline-3carboxylic acid; methanesulfonic acid.

\section{METHOD}

The pefloxacin mesylate was obtained from CDTL, Chalapathi Institute of Pharmaceutical Sciences. Excipients tested were: magnesium stearate, talc powder, microcrystalline cellulose and starch. The mixed samples consisted of equal masses of cefadroxil and each excipient was weighed individually into amber glass flasks to 
originate mass of $20 \mathrm{~g}$ of mixture. Physical mixtures were prepared in proportion $(\mathrm{m} / \mathrm{m})$ 1:1 (Pefloxacin mesylate: excipient) by simple mixing. Differential scanning calorimetry (DSC) study was performed on differential scanning calorimeter, model DSC-Q 20, using aluminium crucibles under nitrogen atmosphere, with a constant flow of $50 \mathrm{~mL} \cdot \mathrm{min}-1$ and a heating rate temperature of $500^{\circ} \mathrm{C}$. Sample with the mass in the range of $5 \mathrm{mg}$ were put into aluminium crucibles, at a heating rate, $\beta$, of $15^{\circ} \mathrm{K} \cdot \mathrm{min}-1$.

\section{RESULTS AND DISCUSSION}

The physical chemical properties and compatibilities of several commonly used pharmaceutical excipients (magnesium stearate, talc, microcrystalline cellulose, starch) with the pefloxacin mesylate were evaluated using thermoanalytical methods. Results and discussions Thermal behaviour and kinetic study of pefloxacin mesylate DSC curves of pefloxacin mesylate (Figure 2) show a sharp exothermic peak at $\sim 290^{\circ} \mathrm{C}$ that corresponds to the thermal decomposition.
The values of activation energy for the mixtures with different excipients are presented in Table 1. Compatibility study of pefloxacin mesylate with excipients DSC curves of the pure pefloxacin mesylate and the 1:1 drug:excipient physical mixtures are shown in Figures 2 and 3. Most of the thermal profiles of the mixtures can be considered as a superposition of the TG and DSC curves of the pure pefloxacin mesylate and the excipients. The DSC method is more sensitive to indicate the compatibility/ incompatibility of the binary mixtures. According to the results obtained from TG curves, the mass losses took place through a different mechanism when the magnesium stearate was mixed with the drug, since the exothermic peak of pefloxacin mesylate shifted from $93.86^{\circ} \mathrm{C}$ (for pefloxacin mesylate ) to $83.22^{\circ} \mathrm{C}$ on DTG curve of the mixture. The melting peak of the drug $\left(290.54^{\circ} \mathrm{C}\right)$ [24] could not be identified on the DSC curve, as it can be seen in Figure 3. The results taken from the TG/DTG and DSC curves of the binary mixtures are collected in Table 1. 


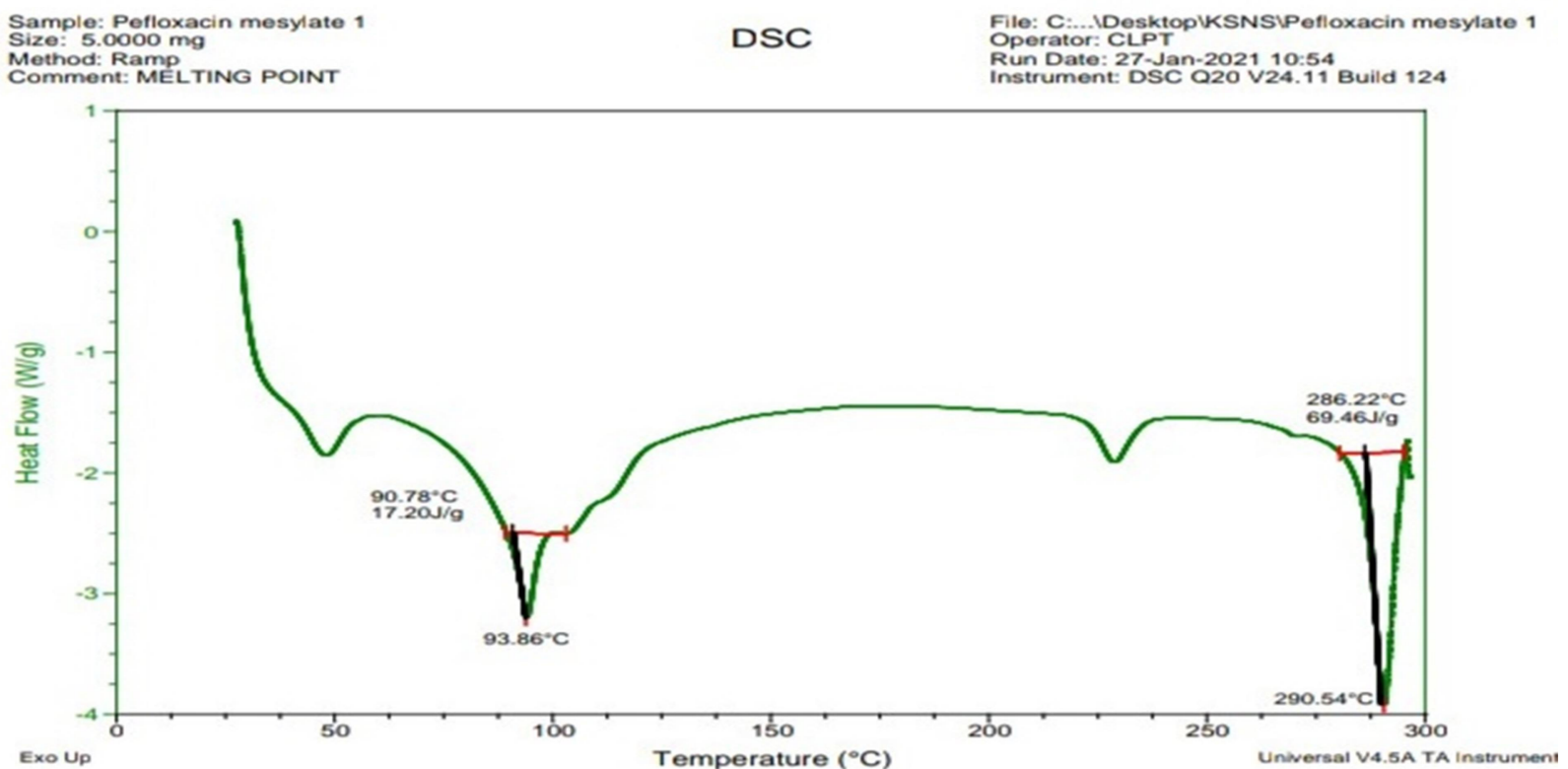

Figure 2: DSC curves of pefloxacin mesylate

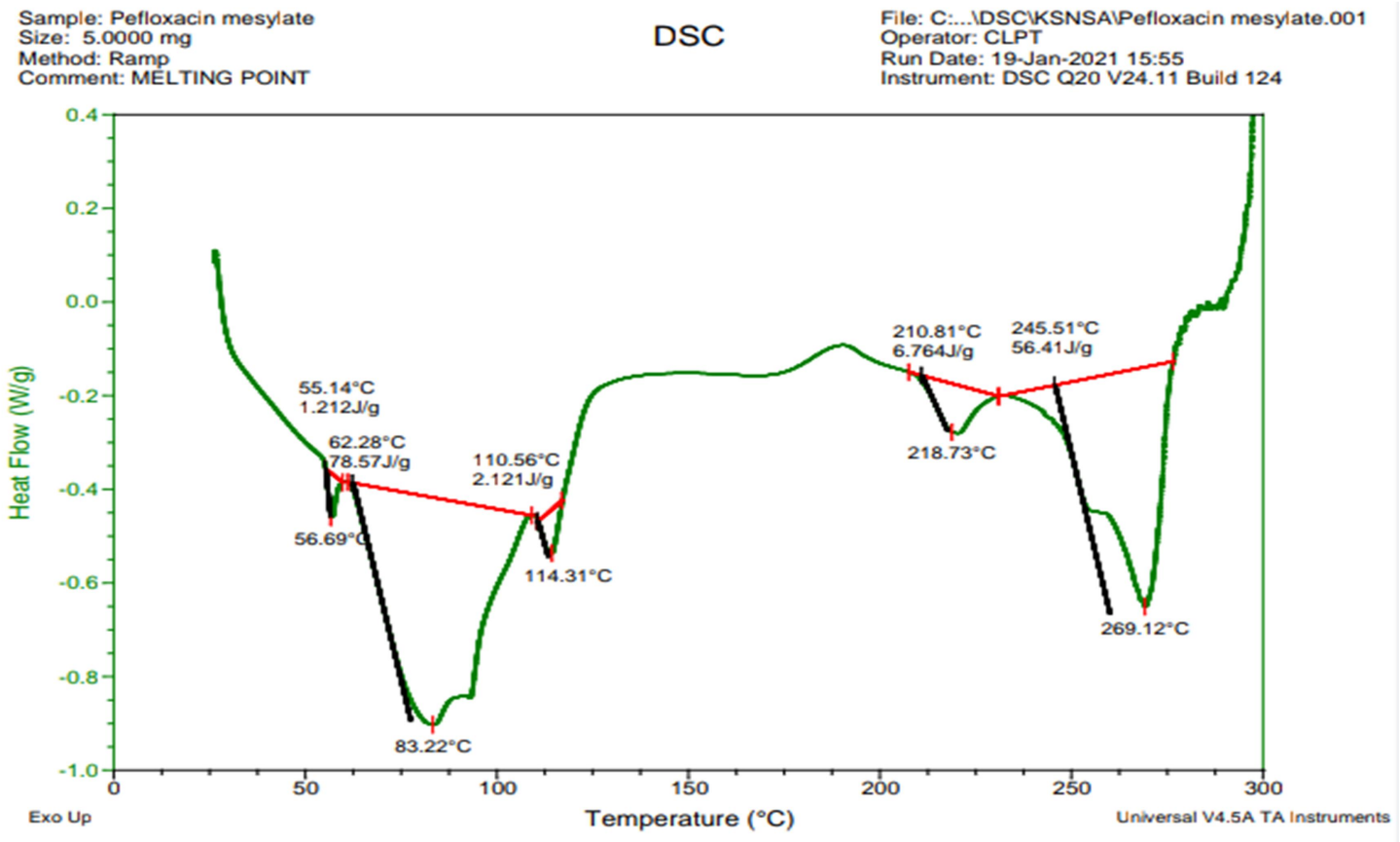

Figure 3: DSC curves of pefloxacin mesylate and pefloxacin mesylate / excipient 1:1 physical mixtures

Table 1: Thermoanalytical data of Pefloxacin Mesylate and of drug:excipient physical mixtures

\begin{tabular}{|c|c|c|}
\hline & Temperature & Heat flow \\
\hline Drug & $93.86^{\circ} \mathrm{C}$ & $17.20 \mathrm{~J} / \mathrm{g}$ \\
\hline Melting point & $290.54^{\circ} \mathrm{C}$ & $69.46 \mathrm{~J} / \mathrm{g}$ \\
\hline Drug with excipients & $\mathrm{83.22}^{\circ} \mathrm{C}$ & $1.212 \mathrm{~J} / \mathrm{g}$ \\
\hline Melting point & $269.12^{\circ} \mathrm{C}$ & $56.41 \mathrm{~J} / \mathrm{g}$ \\
\hline
\end{tabular}




\section{CONCLUSION}

In non-isothermal conditions, the activation energies for the first-step of the decomposition reaction of pefloxacin mesylate were determined. It can be used in the quality control of drug, with a view to improvement of the final product and for the determination of drug quality via the technological parameters. The compatibilities and stabilities of some binary mixtures were studied by using DSC technique. The results showed the utility of thermal analysis as a rapid and convenient method of screening candidate excipients during preformulation studies, because it permits the ascertainment of excipients' compatibility or demonstration of drug-excipient interaction or incompatibility. During this study, it was possible to observe the interactions of the pefloxacin mesylate with talc, magnesium stearate, starch and microcrystalline cellulose. According to the thermoanalytical studies, among all studied mixtures, only one incompatibility was found, the one between pefloxacin mesylate and magnesium stearate, result also sustained by calculated values of the kinetic parameters. However, this excipient is used at low concentration (0.5$2.0 \%$ ) in the pharmaceutical dosage forms so far, another set of stability tests should be carried out to confirm the real impact of this interaction together with other common pharmaceutical excipients.

\section{Acknowledgments}

The authors are grateful to CDTL, Chalpathi Institute of Pharmaceutical Sciences because this work has not been completed without their partial support.

\section{REFERENCES}

[1] Hohne G,Hemminger W, flammersheim H-J. Differential Scanning Calorimetry: An Introduction for Practitioners. Berlin, Germany: Springer - Verlag 1996 .

[2] Privalov PL, Potekhin SA. Scanning microcalorimetry in studying temperature - induced changes in proteins. methods enzymol 1986; 131 $: 4-51$

[3] Even J , Bertault M , Girard A,Delugeard Y, Marqueton Y .optical and Calorimetric studies on the role of lattice mode softening in assisting a thermally enhanced solid state reaction . Chem phys Lett 1997: 267; $585-589$.

[4] Lin LN, Mason AB, Woodworth RC, Brandts JF. Calorimetric studies of the N-terminal half -molecule of transferring and mutant forms modified near the $\mathrm{Fe}(3+)$-binding site . Biochem J 1993: 293: 517 - 522. 
[5] Protasevich I, Ranjbar B, Lobachov V, et al. Conformation and thermal denaturation of apocalmodulin: role of electrostatic mutations. Biochemistry 19 97; 36: 2017-2024. (PubMed)

[6] Ladbury JE, Chowdhry BZ. Sensing the heat: the application of isothermal titration calorimetry to thermodynamic studies of biomolecular interactions. Chem

Biol 1996; 3: 791-801. (PubMed).

[7] Von Stockar U, Marison IW. The use of calorimetryin biotechnology. Bioproc -ess Eng 1989; 40: 93-136.

[8] Weber PC, Salemme R. Applications of calorimetric methods to drug discovery and the study of protein interactions. Curr Opin Struc Biol 2003; 13: 115-121. (PubMed)

[9] Varghesea N, Vivekchanda SRC, Govindaraja A, Rao CNR. A calorimetric investigation of the assembly of gold nanorods to form necklaces. Chem Phys Lett 2008; 450: 340-344.

[10] Haynie DT. Biological Thermodynamics. Cambridge, UK: Cambridge University Press, 2008.

[11] Haines PJ, Reading M, Wilburn FW. Differential thermal analysis and differential scanning calorimetry. In Brown ME. (ed): Handbook of Thermal Analysis and Calorimetry, vol 1 The Netherlands: Elsevier Science BV; 1998; 279-361.

[12] Danley RL. New heat flux DSC measurement technique. Thermochi m Acta 2002; 395: 201-208.

[13] Howell, B. A., J. Therm. Anal. Cal., 93, 2008, p. 27.

[14] Van Holde KE, Curtis Johnson W, Shing Ho P. Thermodynamics and biochemistry. In Principles of Physical Biochemistry, 2nd ed Upper Saddle River, NJ, USA: Pearson Prentice Hall, 2006; 72105

[15] Zucca N, Erriu G, Onnis S, Longoni A. An analytical expression of the output of a power-compensated DSC in a wide temperature range. Thermochim Acta 2002; 143: $117-125$.

[16] Danley RL. Differential Scanning Calorimeter, European Patent 1139 083 A1, 2001. 